\title{
Erratum to: Enhanced magneto-optic activity of magnetite-based ferrofluids subjected to gamma irradiation
}

Manasi Devi · Rupali Das · Dambarudhar Mohanta •

Kishor Kumar Baruah • Abhijit Saha

Published online: 14 December 2011

(C) Springer-Verlag 2011

Erratum to: Appl Phys A

DOI 10.1007/s00339-011-6678-4

Due to a processing error, the presentation of Fig. 1a was incorrect. The corrected Fig. 1 is given below.

The online version of the original article can be found under doi:10.1007/s00339-011-6678-4.

M. Devi · R. Das · D. Mohanta $(\varangle) \cdot$ K.K. Baruah

Nanoscience and Soft Matter Laboratory, Department of Physics,

Tezpur University, PO Napaam, Assam 784028, India

e-mail: best@tezu.ernet.in

Fax: +91-3712-267005/6

A. Saha

UGC-DAE Consortium for Scientific Research, Kolkata Centre,

III/LB-8 Bidhannagar, Kolkata 700 098, India
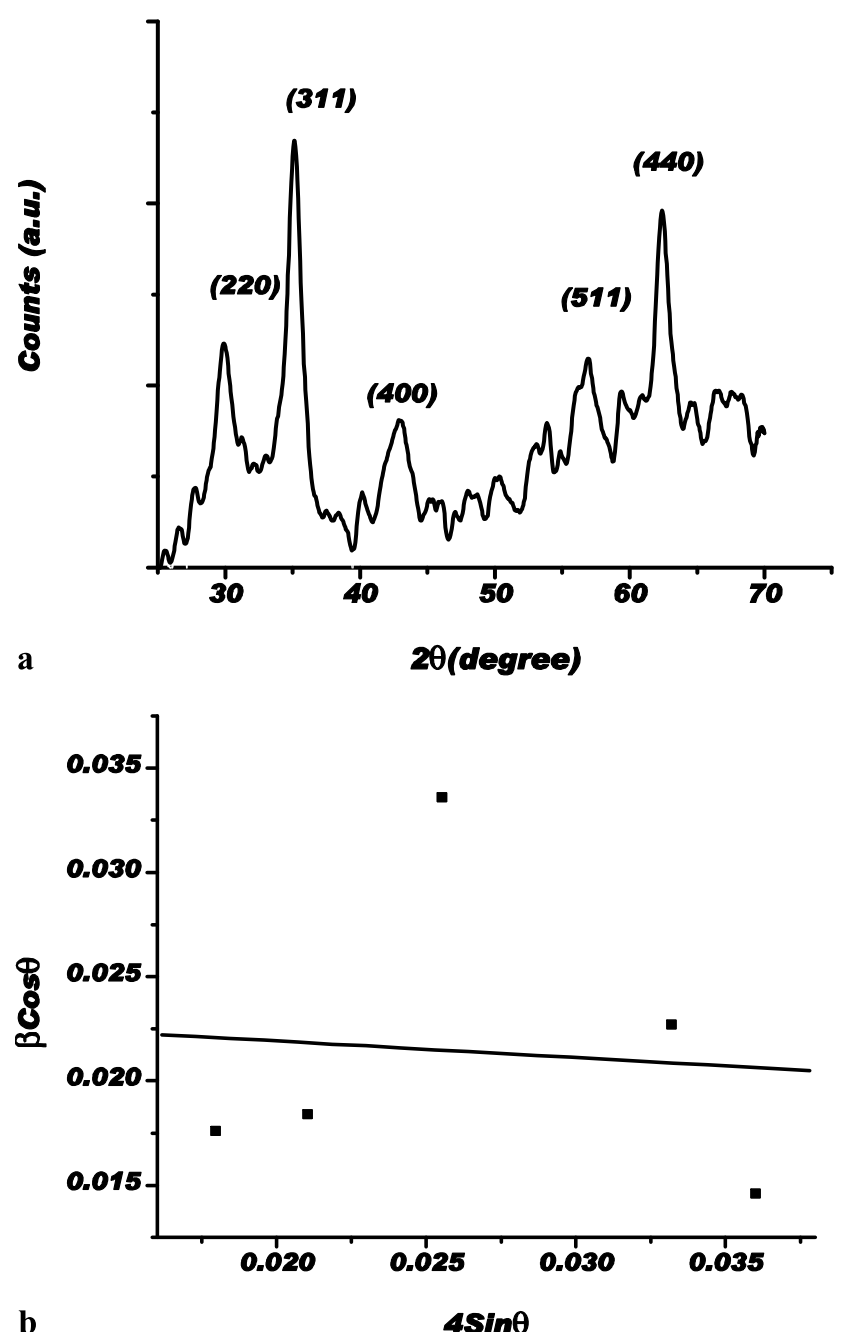

Fig. 1 (a) XRD pattern of the synthesized magnetite $\left(\mathrm{Fe}_{3} \mathrm{O}_{4}\right)$ particles, and (b) W-H plot obtained using major diffraction peaks from (a) 